\title{
INFLUENCE OF MODIFICATION ON MICROSTRUCTURE DEGRADATION OF AISi12 ALLOY EXPOSED TO THE CORROSION ENVIRONMENT
}

\author{
Franjo KOZINA, Zdenka ZOVKO BRODARAC \\ University of Zagreb Faculty of Metallurgy, Sisak, Croatia, EU, fkozin@simet.hr, zovko@simet.hr
}

https://doi.org/10.37904/metal.2020.3596

\begin{abstract}
The corrosion resistance of aluminum-silicon (Al-Si) foundry alloys is a result of microstructure development influenced by melt treatment and solidification. As a part of the main eutectic $\left(\alpha_{A l}+\beta_{S \mathrm{Si}}\right), \beta_{\mathrm{Si}}$ particles are cathodic with respect to the $\alpha_{A I}$ matrix enabling micro-galvanic couple formation and localized corrosion. Despite its high polarization and low current density, increase in the eutectic $\left(\alpha_{A l}+\beta_{\text {Si }}\right)$ will contribute to the microstructure degradation of an alloy in corrosive environment. The research was performed in order to estimate the influence of eutectic $\beta_{\text {si }}$ particles size on the microstructure degradation of AISi12 alloy with mixed morphology of eutectic $\left(\alpha_{A I}+\beta_{S_{i}}\right)$. The results of light microscopy indicated preferred initiation and progress of cavities involving modified eutectic $\left(\alpha_{\mathrm{Al}}+\beta_{\mathrm{Si}}\right)$ with eutectic $\beta_{\mathrm{Si}}$ particles of smaller average particle size. The unmodified eutectic $\left(\alpha_{\mathrm{Al}}+\beta_{\mathrm{Si}}\right)$ with lamellar morphology and dendrites of primary $\alpha_{\mathrm{Al}}$ phase were not visually affected by degradation. The average cavity size and $\mathrm{pH}$ value of the solution increase with the increasing exposure time, while microstructure degradation rate decreases.
\end{abstract}

Keywords: AlSi12, eutectic modification, particle size, corrosion environment, microstructure degradation

\section{INTRODUCTION}

The corrosion resistance of aluminum-silicon (Al-Si) foundry alloy derives from chemical composition, value of secondary dendrite arm spacing (SDAS) and anodic or cathodic behavior of the main or secondary phase components [1]. Although, size of the SDAS has a direct influence on mechanical properties, it is not clear if decrease in the SDAS improves resistance to microstructure degradation in corrosive environment. In order to understand microstructures tendency towards degradation, SDAS needs to be correlated with phase distribution into the interdendritic region and its anodic/cathodic behavior with respect to the $\alpha_{A 1}$ matrix [2]. As a part of the main eutectic $\left(\alpha_{\mathrm{Al}}+\beta_{\mathrm{Si}}\right)$, $\beta_{\mathrm{Si}}$ particles are cathodic with respect to the $\alpha_{\mathrm{Al}}$ matrix causing the formation of micro-galvanic couples and localized corrosion phenomena [3]. Even due the effect of $\beta$ si particles on microstructure degradation is minimal, due to its high polarization and low current density, increase of eutectic $\left(\alpha_{\mathrm{Al}}+\beta_{\mathrm{Si}}\right)$ ratio in microstructure will have deleterious effect on the alloy's microstructure [4].

The chemical modification of Al-Si foundry alloys influences eutectic $\left(\alpha_{A l}+\beta_{S i}\right)$ solidification and leads to structural transformation of the eutectic $\beta$ si phase from course lamellar to fine fibrous morphology. This structural refinement, caused by the addition of modifiers, increases circularity and reduces particle size and aspect ratio of modified eutectic $\beta$ si phase [5]. Consequently, modification has direct influence on fracture surface geometry as well as beneficial influence on ductility, toughness, tensile strength, and elongation [6].

The goal of the research is to estimate the influence of $\beta$ si particle size and distribution on the microstructure degradation of eutectic AISi12 alloy in the corrosive environment. The applied method simulates various types of outdoor services, especially in marine and automotive applications. The progress of the accelerated corrosion process and its impact on the macrostructure and microstructure will be estimated visually using light microscopy. 


\section{MATERIALS AND METHODS}

The synthesis of eutectic AISi12 alloy began by remelting of the AISi12 block followed by chemical composition augmenting through the additions of AISi50\%, AITi10 and AIMn master alloys. After stirring with argon and chemical degasing, the alloy was modified by adding metallic sodium packed in vacuum sealed aluminum can. In order to obtain modified and unmodified morphology of eutectic $\beta_{\text {Si }}$ particles, the samples were taken 10 min (sample 1) and $60 \mathrm{~min}$ (sample 2) after the addition of the modifier by pouring into a permanent steel mould. Approximately $2 \mathrm{~min}$ after pouring the samples were quenched in water.

Chemical composition of the synthesized alloy was determined spectroscopically using SPECTRO MAX $x$ LMM 04 spectrometer.

The samples for metallographic analysis were prepared using standard grinding and polishing techniques. The samples for macrostructural analysis were etched using Poulton's etching solution. The macrostructure was observed using stereo microscope Olympus SZ11.

The samples for light microscopy were etched in $0.5 \%$ aqueous hydrofluoric acid solution. The microstructure was analyzed using the Olympus GX51 inverted metallographic microscope equipped with AnalySIS Materials Research Lab software support. Application of the particle analysis enabled particle count and area classification of eutectic $\beta$ si particles. Five micrographs per sample were analyzed by setting threshold at the binary images.

Before exposure to the corrosive environment, the samples were grinded and mounted in inert resin. The mounting was performed in order to prevent spontaneous degradation from all sides.

The solution for the corrosion testing was obtained by dissolving $234 \mathrm{~g}$ of sodium chloride $(\mathrm{NaCl})$ and $50 \mathrm{~g}$ of potassium nitrate $\left(\mathrm{KNO}_{3}\right)$ in water. Afterwards, $6.3 \mathrm{ml}$ of $\mathrm{HNO}_{3}$ were added and the solution was diluted to 1 I by adding distilled water. The obtained solution had the apparent $\mathrm{pH}$ of 0.4 . The samples were immersed in the solution for 5, 24, 48 and $72 \mathrm{~h}$. After words, the samples were neutralized in concentrated $\mathrm{HNO}_{3}$, rinsed in distilled water, alcohol and dried in hot air. The Laboratory pH Meter inoLab LeV1 was used to measure changes in $\mathrm{pH}$ of the solutions after the samples were removed.

By calculating loses of mass with respect to exposure time, the microstructure degradation rate was calculated.

The macrostructure was analysed on the exposed surface of the samples, while microstructural analysis was performed on the cross-section of the samples after standard metallographic preparation and etching in $0.5 \%$ aq HF solution. Analysis of the cross-section enabled cavity depth measurements.

\section{RESULTS AND DISCUSSION}

The results of chemical analysis are given in Table 1.

Table 1 Chemical composition of the produced alloy (wt\%)

\begin{tabular}{|c|c|c|c|c|c|c|c|c|}
\hline $\mathbf{S i}$ & $\mathbf{F e}$ & $\mathbf{M n}$ & $\mathbf{M g}$ & $\mathbf{N i}$ & $\mathbf{S n}$ & $\mathbf{T i}$ & $\mathbf{N a}$ & $\mathbf{A l}$ \\
\hline 12.9 & 0.151 & 0.077 & 0.065 & 0.006 & 0.065 & 0.081 & 0.014 & Balance \\
\hline
\end{tabular}

The chemical composition of the produced alloy is in accordance with EN 1706:2010 for EN AC 4410 (EN AC AISi12) alloys. The addition of $\mathrm{Na}$ is sufficient to fully modify eutectic $\left(\alpha_{\mathrm{Al}}+\beta_{\mathrm{Si}}\right)$ from course lamellar to fine fibrous morphology.

The macrostructure and microstructure of the samples are given in Figure 1. 


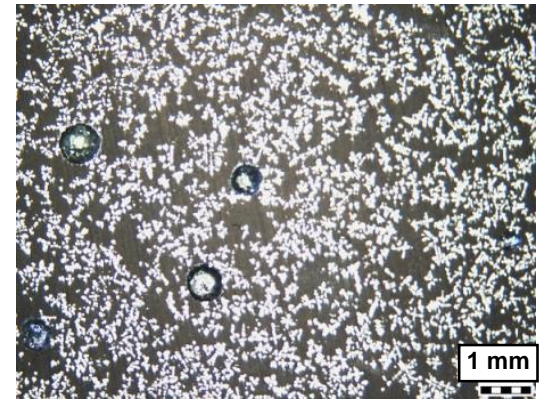

a)

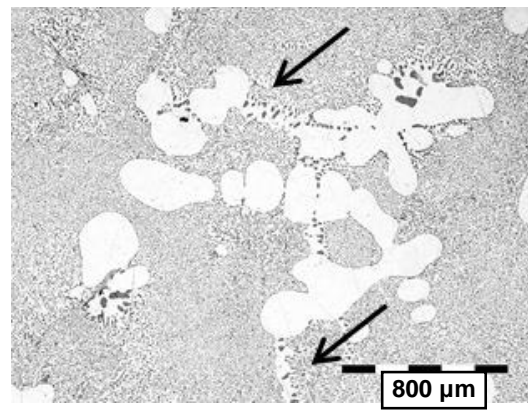

c)

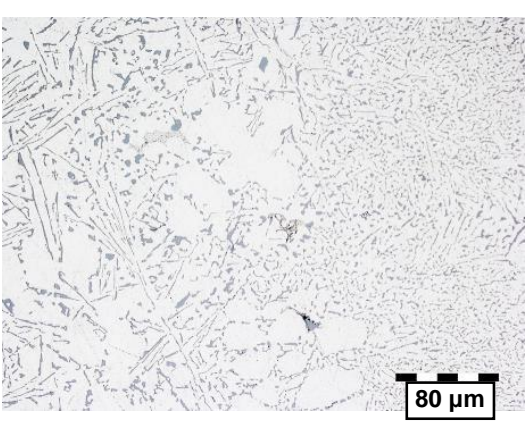

d)

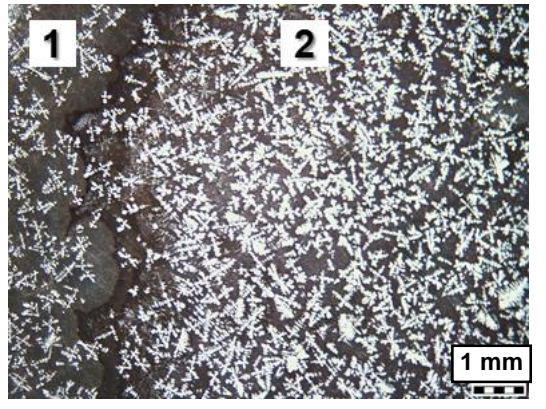

b)

Figure 1 Micrographs of: a) macrostructure of the sample 1, b) macrostructure of the sample 2, c) microstructure of the sample 1, d) microstructure of the sample 2 in the area 1, e) microstructure of the sample 2 in the area 2

The macrostructure of the samples consists of a dendritic network of primary $\alpha_{A I}$ phase (Figures $1 \mathbf{a}, \mathbf{b}$, bright areas) and interdendritic areas filled with eutectic $\left(\alpha_{A l}+\beta_{\mathrm{Si}}\right)$ (Figures $\mathbf{1} \mathbf{a}, \mathbf{b}$, dark areas). The macrostructure of the sample 2 also reveals the presence of solid-liquid interface with growth direction from surface to the center of the sample. The quenching of the sample enabled formation of central zone (Figure $1 \mathbf{b}$, zone 2) and surface zone with average thickness of $2.69 \mathrm{~mm}$ (Figure $1 \mathbf{b}$, zone 1$)$. In the sample 1 eutectic $\left(\alpha_{\mathrm{Al}}+\beta_{\mathrm{Si}}\right)$ is fully modified with fine fibrous morphology (Figure $1 \mathbf{a}$ ). Due to the over modification with $\mathrm{Na}$, the coarsening of the eutectic $\beta_{\text {si }}$ particles and the overgrowth of the $\alpha_{A I}$ matrix can be seen at the grain boundaries (Figure 1 c). The microstructural analysis of the sample 2 indicates the difference in eutectic $\left(\alpha_{A l}+\beta_{S i}\right)$ morphology between the zones. The surface zone eutectic $\left(\alpha_{A l}+\beta_{S i}\right)$ has lamellar morphology (Figure $\left.1 \mathbf{d}\right)$, while the eutectic $\left(\alpha_{A l}+\beta_{S i}\right)$ in central zone is fully modified (Figure $\left.1 \mathbf{e}\right)$.

The results of particle analysis are given in Table 2.

Table 2 Results of particle analysis

\begin{tabular}{|c|c|c|c|c|}
\hline Sample & Zone & $\begin{array}{c}\text { Particle count } \\
(\mu \mathrm{m})\end{array}$ & $\begin{array}{c}\text { Particle area } \\
(\mu \mathrm{m})\end{array}$ & $\begin{array}{c}\text { Average particle size } \\
(\mu \mathrm{m})\end{array}$ \\
\hline 1 & $/$ & 3230.6 & 6739.36 & 2.09 \\
\hline 2 & surface & 1400.2 & 7465.05 & 5.33 \\
\hline 2 & central & 1911.6 & 1906.11 & 1.00 \\
\hline
\end{tabular}

The results of the particle analysis indicate the highest particle count in sample 1 with average particle size of $2.09 \mu \mathrm{m}$ (Table 1). The lowest particle count was measured in the surface zone of sample 2 with largest average particle size of $5.33 \mu \mathrm{m}$. The central zone of sample 2 has the smallest average particle size of $1.0 \mu \mathrm{m}$ (Table 1).

The example of the samples macrostructure after $48 \mathrm{~h}$ of exposure is given in Figure 2. 


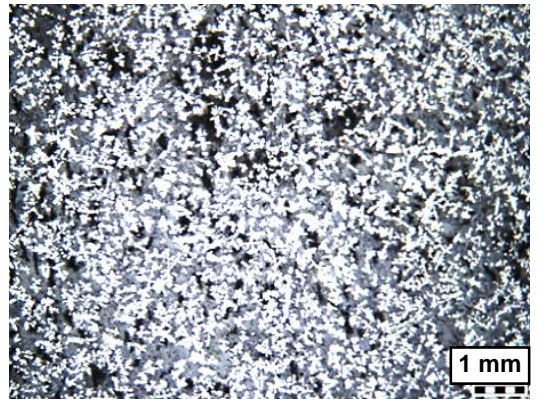

a)

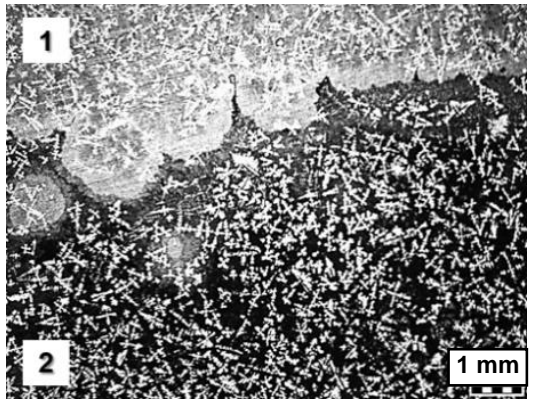

b)

Figure 2 Macrostructure of samples at the magnification of $12.5 \mathrm{X}$ :

a) Sample 1, b) Sample 2

During $48 \mathrm{~h}$ of exposure the microstructure degradation of sample 1 comprehended cavities formation in the interdendritic areas of primary $\alpha_{A I}$ phase (Figure 2 a, black areas). Exposure of sample 2 to the corrosive environment indicated quenched solid-liquid interface and small spherical colonies (Figure $\mathbf{2}$ b). The central zone of the sample 2 shows more significant microstructural degradation compared to the surface zone (Figure $\mathbf{2}$ b, black areas).

The microstructure of the samples after 5, 24 and $72 \mathrm{~h}$ exposure is shown in Figure 3.

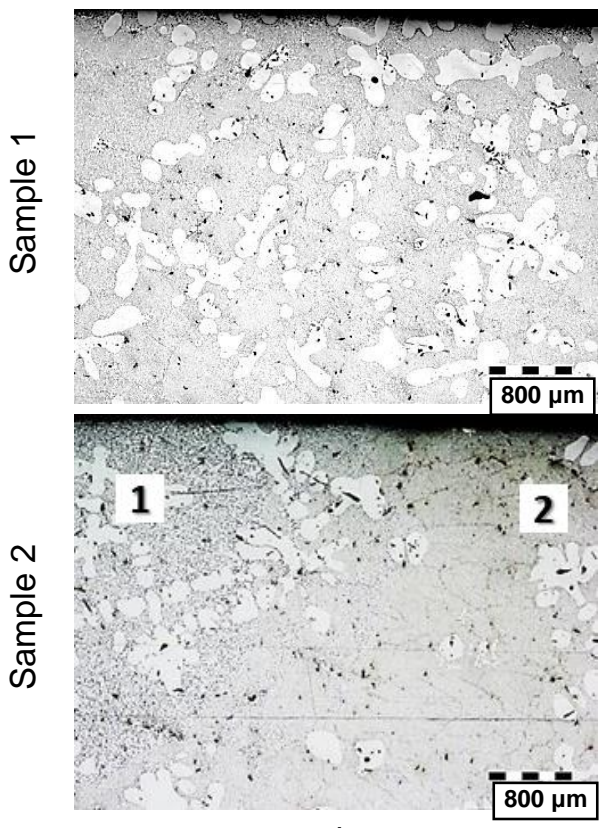

$5 \mathrm{~h}$

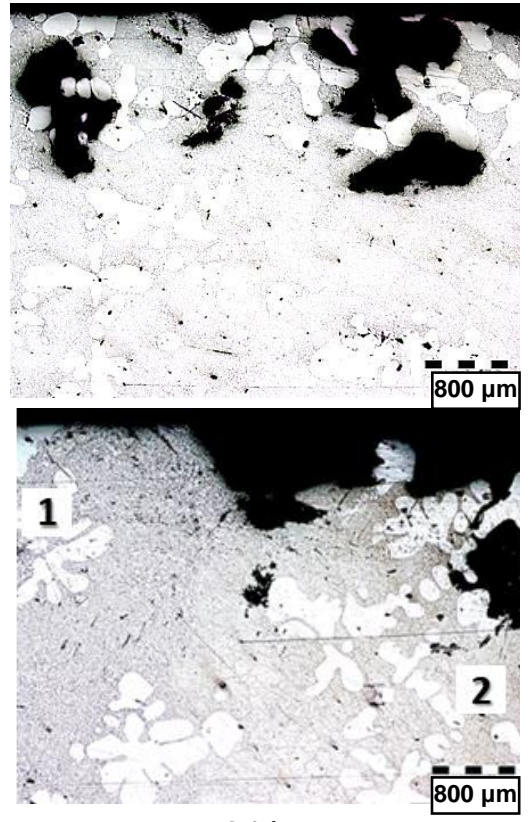

$24 \mathrm{~h}$

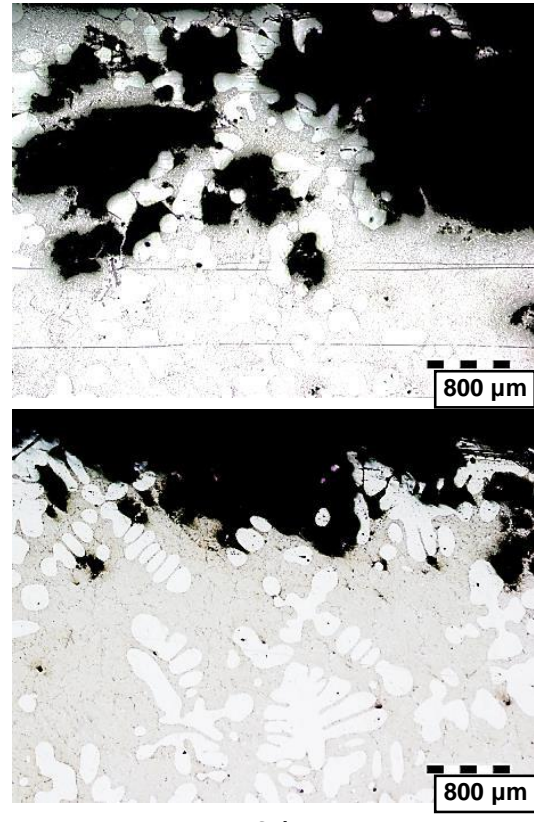

$72 \mathrm{~h}$

Figure 3 Microstructure of the samples after 5, 24, $72 \mathrm{~h}$ exposure to the corrosive environment

The cross-section of the sample $1,5 \mathrm{~h}$ after the exposure shows negligible microstructural degradation. The cavities can be seen 24 and $72 \mathrm{~h}$ after the beginning of the testing. The cavities initiate at the exposed surface and progress deeper into the material affecting the eutectic $\left(\alpha_{\mathrm{Al}}+\beta_{\mathrm{Si}}\right)$ located in the interdendritic network of primary $\alpha_{A I}$ phase (Figure 3, sample 1). The microstructure of the sample 2 after $5 \mathrm{~h}$ of exposure shows the lack of cavities at the solid-liquid interface. However, the small cavities forming at the surface of the sample can be found in central zone. The microstructure of the sample after $24 \mathrm{~h}$ of exposure shows presence of cavities at the solid-liquid interface progressing into the central zone with average size of eutectic $\beta$ si particle $1.00 \mu \mathrm{m}$ (Table 2). In next $72 \mathrm{~h}$, the cavities progress deeper into the material affecting the modified eutectic 
$\left(\alpha_{\mathrm{Al}}+\beta_{\mathrm{Si}}\right)$. The unmodified eutectic $\left(\alpha_{\mathrm{Al}}+\beta_{\mathrm{Si}}\right)$ with average size of eutectic $\beta_{\mathrm{Si}}$ phase particle $5.33 \mu \mathrm{m}$ (Table 2) is not significantly affected by the corrosion processes (Figure 3, sample 2).

The average cavity depth and rate of the microstructure degradation are shown in Figure 4, while the changes in $\mathrm{pH}$ value are given in Table 3.

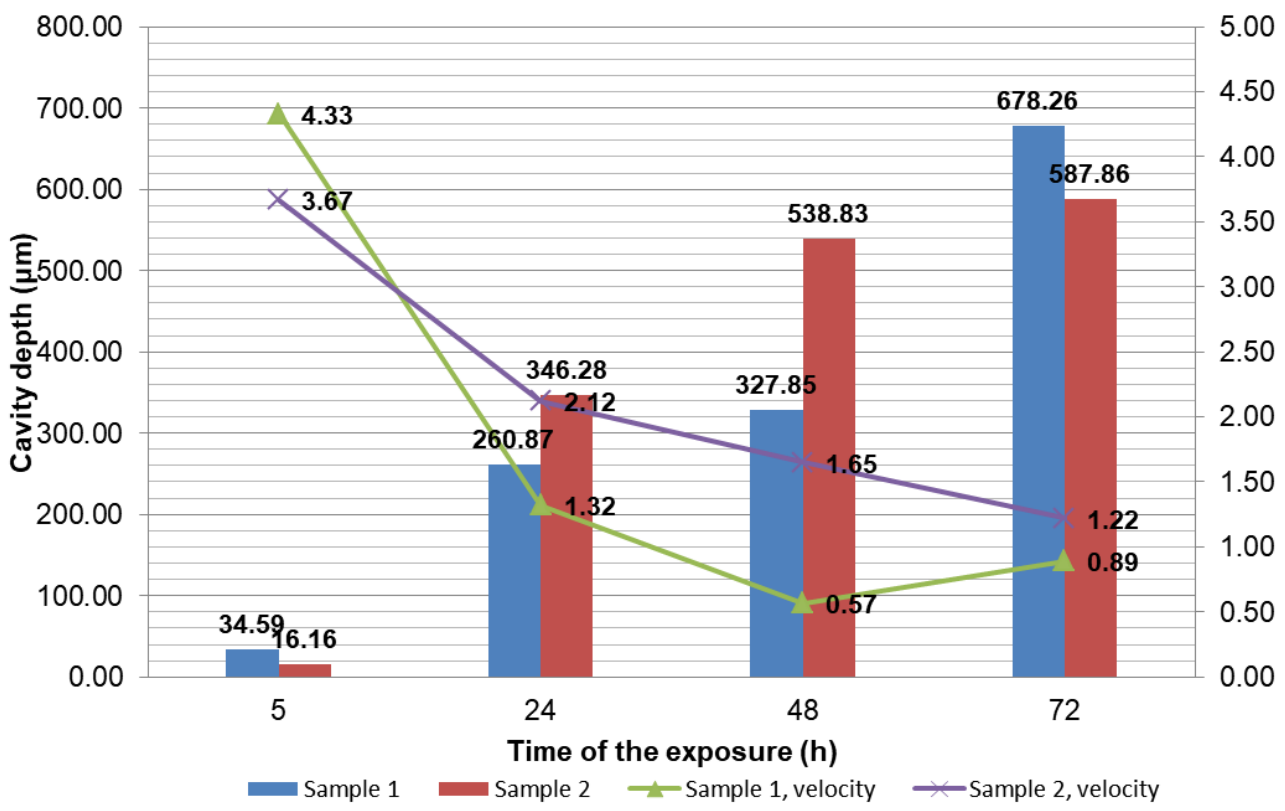

Figure 4 The average cavity depth and microstructure degradation rate

Table 2 The changes in $\mathrm{pH}$ value per sample and corrosion exposure time

\begin{tabular}{|c|c|c|c|c|}
\hline \multirow{2}{*}{ Sample } & \multicolumn{4}{|c|}{ Corrosion exposure time $(\mathrm{h})$} \\
\cline { 2 - 5 } & $\mathbf{5}$ & $\mathbf{2 4}$ & $\mathbf{4 8}$ & $\mathbf{7 2}$ \\
\hline 1 & 0.38 & 0.53 & 0.88 & 1.14 \\
\hline 2 & 0.35 & 0.65 & 1.31 & 1.59 \\
\hline
\end{tabular}

During the first $5 \mathrm{~h}$ the cavities with the average cavity size of $34.59 \mu \mathrm{m}$ can be observed at the surface of the sample 1. The cavities form with the rate of $4 \cdot 33 \cdot 10^{-7} \mathrm{~g} / \mathrm{s}$ (Figure 4). The solution pH value decreases to 0.38 (Table 2). After $24 \mathrm{~h}$ the cavities with the average cavity size of $280.87 \mu \mathrm{m}$ were formed with rate of $1.32 \cdot 10^{-7}$ $\mathrm{g} / \mathrm{s}$ (Figure 4). The $\mathrm{pH}$ value of the solution increases to 0.53 (Table 2). After $48 \mathrm{~h}$ of exposure the microstructure degradation rate decreases to $0.57 \cdot 10^{-7} \mathrm{~g} / \mathrm{s}$ while average cavity size increases to $328 \mu \mathrm{m}$ (Figure 4). The solution $\mathrm{pH}$ value increases to 0.88 (Table 2). Towards the end of the exposure the microstructure degradation rate increases to $0.89 \cdot 10^{-7} \mathrm{~g} / \mathrm{s}$ resulting in the cavity formation with average cavity size of $678 \mu \mathrm{m}$ (Figure 4). The pH value increases to 1.14 .

During the first $5 \mathrm{~h}$ the cavities with the average cavity size of $16 \mu \mathrm{m}$ were formed at the surface of the sample 2. The cavities form with the rate of $3.67 \cdot 10^{-7} \mathrm{~g} / \mathrm{s}$ (Figure 4). The solution $\mathrm{pH}$ value decreases to 0.35 (Table 2). After $24 \mathrm{~h}$ the cavities with the average cavity size of $346 \mu \mathrm{m}$ were formed with rate of $2.12 \cdot 10^{-7} \mathrm{~g} / \mathrm{s}$ (Figure 4). The $\mathrm{pH}$ value of the solution increases to 0.65 (Table 2). After $48 \mathrm{~h}$ of exposure the microstructure degradation rate decreases to $1.65 \cdot 10^{-7} \mathrm{~g} / \mathrm{s}$ while average cavity size increases to $539 \mu \mathrm{m}$ (Figure 4). The solution's $\mathrm{pH}$ value increases to 1.31 (Table 2). Towards the end of the exposure the microstructure degradation rate decreases to $1.22 \cdot 10^{-7} \mathrm{~g} / \mathrm{s}$ resulting in the cavity formation with average cavity size of $588 \mu \mathrm{m}$ (Figure 4). The $\mathrm{pH}$ value increases to 1.59 . 
The results of the measurements indicate the constant increase in average cavity size and $\mathrm{pH}$ value with the increase in corrosion exposure time. On the other hand the microstructure degradation rate decreases with the increase in exposure time. Compared to sample 2, the sample 1 shows more significant microstructure degradation and higher corrosion rate at $5 \mathrm{~h}$ and $72 \mathrm{~h}$.

\section{CONCLUSION}

In order to estimate the influence of eutectic $\beta_{\text {si }}$ particle size and distribution on the microstructure degradation in corrosive environment, AISi12 alloy with modified and unmodified morphology of eutectic $\left(\alpha_{A I}+\beta_{S_{i}}\right)$ was produced.

The microstructural analysis indicated the formation of cavities in both samples. The cavities initiated at the exposed surface and progressed deeper into the material affecting the eutectic $\left(\alpha_{\mathrm{Al}}+\beta_{\mathrm{si}}\right)$. The most significant microstructure degradation was observed in the central zone of the sample 2 with the smallest average particle size of $\beta_{\text {si }}$ particle $1.0 \mu \mathrm{m}$. On the other hand, the unmodified eutectic $\left(\alpha_{\mathrm{Al}}+\beta_{\mathrm{Si}}\right)$ with average particle size of $\beta$ si particle $5.3 \mu \mathrm{m}$, located in surface zone of the sample 2, was not visually affected by the microstructural degradation. The dendritic network of primary $\alpha_{A I}$ phase was not visually affected by the microstructural degradation. The average cavity size increases with the increase in the exposure time. The microstructure degradation rate decreases with the increase in $\mathrm{pH}$ value.

Performed investigation indicated that shorter modification $(10 \mathrm{~min})$ shortened the solidification interval and encouraged the natural solidification conditions (without solid-liquid interface). Those conditions comprehend homogeneous microconstituents distribution, smaller in size (Sample 1). As a part of eutectic phase, fibrous $\beta_{\text {Si }}$ was more resistant to corrosion environment till $24 \mathrm{~h}$ of exposure, according to cavity depth measurement.

\section{ACKNOWLEDGEMENTS}

\section{Investigations were performed within the research topic "Design and Characterization of Innovative Engineering Alloys", Code: FPI-124-2019-ZZB funded by University of Zagreb and infrastructural scientific project: Center for Foundry Technology, Code: KK.01.1.1.02.0020 funded by European \\ Regional Development Fund. Personal gratitude goes to the Mrs. Milici Marjanović for her assistance in the experiment.}

\section{REFERENCES}

[1] ŠĆEPANOVIĆ, J., ASANOVIĆ, V., RADONJIĆ, D., VUKSANOVIĆ, D., HERENDA, S., KORAĆ, F. BIKIĆ, F. Mechanical properties and corrosion behavior of AI-Si alloys for IC engine. Journal of the Serbian Chemical Society. 2019, vol. 84, no. 5, pp. 503-516.

[2] BERLANGA, C., BAKEDANO, A., DE CIRIZA, A. PEREZ RIVERO, P. J., MENDEZ, S., RODRIGUEZ, R., NIKLAS, A. Evaluation of the corrosion resistance of a new AISi10MnMg(Fe) secondary alloy. Materials Today: Proceedings, 2018, vol. 10, pp. 312-318.

[3] ARTHANARI, S., JANG, J. C., SHIN, K. S. Corrosion performance of high pressure die-cast Al-Si-Mg-Zn alloys in 3.5 wt\% $\mathrm{NaCl}$ solution. Journal of Alloys and Compounds. 2018, vol. 783, pp. 494-502.

[4] DUYGUN, I. K., HAPÇI AĞAOĞLU, G., DISPINAR, D., ORHAN, G. Time-dependent corrosion properties of Srmodified AISi9 alloy analyzed by electrochemical techniques. Journal of Alloys and Compounds. 2019, vol. 803, pp. 786-794.

[5] STJOHN, D., MCDONALD, S., DARLAPUDI, A. A new perspective on the nucleation, growth morphology and modification of the silicon phase during the formation of eutectic Al-Si grains. JoM. 2019, vol. 71, no. 1, pp. 391396, 2019.

[6] KRUGlova, A., ROLAND, M., DIEBEls S., DAHMEN, T., SLUSALLEK, P., MÜCKLICH, F. Modelling and characterization of ductile fracture surface in Al-Si alloys by means of Voronoi tessellation. Materials Characterization. 2017, vol. 131, pp. 1-11. 